\title{
Building Scaffolds in the Field: The Benefits and Challenges of Teacher Candidate Peer Mentorship
}

\author{
Arlene L. Grierson \\ Maria Cantalini-Williams \\ Taunya Wideman-Johnston \\ Stephen Tedesco \\ Nipissing University
}

\begin{abstract}
This paper details the perspectives of teacher candidates who participated in a paired practicum peer mentorship program. A total of 227 dyads of novice first year and mentor second or third year concurrent education students took part in a program that was developed with the intent of providing scaffolding through opportunities to engage in reciprocal learning. Of the 454 potential study participants, 166 elected to complete anonymous electronic post-program surveys documenting their perceptions of the benefits and challenges of this field experience model. Findings indicated that the majority perceived the practicum peer mentorship program to provide increased support through reciprocal learning and collegial collaboration, which enhanced their confidence and professional growth. Challenges included adjusting to the paradigm shift of paired practicum experiences, which necessitates deviating from perceptions of teaching as independent practice and developing contextual supports in collaboration with school board partners. The findings and implications may provide direction for teacher educators seeking to implement paired practicum experiences in attempts to scaffold candidates' growth and promote their enculturation into collaborative communities of professional practice.
\end{abstract}

Keywords: paired practicum, field experience, peer mentorship, reciprocal learning, collaborative practice

Arlene Grierson, Assistant Professor at the Brantford Campus of Nipissing University, teaches concurrent education courses in Language and Literacy. Primary research interests: the effects of various models and systems of professional learning on teachers' knowledge, classroom practices, and associated beliefs, with particular attention to the factors that affect teacher change and processes through which it occurs. Email: arleneg@nipissingu.ca

Maria Cantalini-Williams is Associate Dean (Interim) of the Brantford Campus of Nipissing University, Schulich School of Education. She has taught education courses at the pre-service, in-service and master's levels. Research interests: teacher education pedagogy; alternative practicum placements including international experiences; early education; examining 'success in school' as affected by month of birth and gender. Email: mariac@ nipissingu.ca

Taunya Wideman-Johnston teaches courses in developmental psychology at Nipissing University's Brantford campus. Her primary research focus is the academic experiences of students with chronic illness. In addition, her research has focused on pre-service education practicum models and candidates' experiences integrating mobile technology devices during pre-service education. Emal: taunyaw@ nipissingu.ca

Stephen Tedesco is an instructional designer at the Nipissing University Centre for Flexible Learning. He is pursuing an EdD in Educational Technology at the University of Calgary. Stephen's doctoral research focuses on how educators can use handheld mobile devices to create situated learning experiences. Email: stephent@nipissingu.ca

Brock Education, Volume 20, No. 2, Spring 2011, 85-103 


\section{Introduction}

Becoming a teacher is a complex journey that is fraught with the complexities of concurrently developing knowledge for practice, which is empirically evidenced, and knowledge of practice derived from experience in the classroom context (Cochran-Smith \& Lytle, 1999). While the value of field experiences is well established, a persistent problem in teacher education is providing support as candidates endeavour to make sense of the knowledge of practice derived through their practicum placements, by relating it to the theoretical knowledge developed through coursework (Cochran-Smith \& Lytle, 1999; Falkenberg \& Smits, 2010; Long \& Steward, 2004; Loughran, 2006; Mueller \& Skamp, 2003). Research has documented that paired practicum experiences (i.e., dyads of candidates placed in the same classroom) can increase support for teacher candidates (Bullough, Young, Birrel, Clark, Egan, Erickson, Frankovich, Brunetti, \& Welling, 2003; Bullough, Young, Erickson, Birrell, Clark, \& Egan, 2002; Gardiner \& Robinson, 2009; Goodnough, Osmond, Dibbon, Glassman, \& Stevens, 2009; Walsh \& Elmslie, 2005). However, relatively little research has explored paired practicums, with most studies focused on the experiences of small sample populations. The study described herein sought to document the experiences of a larger participant pool and extend insights gleaned through investigations of paired practicum participants at the same stage of program completion, by documenting the benefits and challenges of paired practicum mentorship between novice and more experienced teacher candidates.

In this paper we profile the experiences of participants in a practicum peer mentorship program that attempted to provide support by placing each novice first year concurrent education candidate in the same practicum setting as a mentor second or third year teacher candidate. We first provide an overview of the literature related to the paradigm shift to collaborative practice, teacher mentorship programs, and the complexities of field experiences. Next follows our methodology, which includes descriptions of the context and participants, as well as our data collection and analysis methods. In presenting our findings we highlight participants' perceptions of this program, which reveal that this reciprocal learning mentorship model holds significant promise for scaffolding candidates' growth through collaborative practice. Challenges include adjusting to the paradigm shift of paired practicum experiences, which necessitates deviating from perceptions of teaching as independent practice. Facilitating this shift requires contextual supports and ongoing collaboration with school board partners.

\section{Background Literature}

From the perspective of many teacher candidates, "good teaching looks easy" (Falkenberg \& Smits, 2010 p. 19). Accordingly, teacher education programs must enhance candidates' understandings of pedagogical complexity through coursework and field experiences (Loughran, 2006). There is little doubt that field experiences are an integral component of teacher education (Falkenberg \& Smits, 2010; Loughran, 2006). Nonetheless, integrating university course-based and field-based programming, while responding to the evolving context of educational practice, brings forth many challenges (Cochran Smith \& Lytle, 2009; Falkenberg \& Smits, 2010; Le Cornu \& Ewing, 2008; Long \& Stuart, 2004). 


\section{The Paradigm Shift to Collaborative Practice}

Although teaching was once perceived to be autonomous practice, concomitant with increased understandings that students socially construct knowledge, the importance of teachers engaging in collaborative practice has been acknowledged widely (Cochran-Smith \& Lytle, 1999; Falkenberg \& Smits, 2010; Fullan, Hill \& Crevola, 2006; Le Cornu \& Ewing, 2008). This paradigm shift has affected teacher practitioners' professional learning opportunities and promoted an emphasis on collaborative inquiry-based learning and classroom-based peer coaching, which includes co-planning and co-teaching (Cochran-Smith \& Lytle, 1999, 2009; Fullan et al., 2006; Knight, 2009). However, some teachers are resistant to making their private pedagogical thoughts and actions public during collaborative professional learning, which has been attributed in part, to long-held perceptions of teaching as independent practice (Fullan et al., 2006; Knight, 2009). The shift to expectations of collaborative practice affects teacher candidates who enter their profession as insiders who have gained considerable understandings of teaching through their biographical experiences as students (Lortie, 1975; Pajares, 1992).

Teacher candidates begin their professional preparation programs after thousands of hours in their "apprenticeship of observation" (Lortie, 1975, p. 62). The understandings and beliefs derived through their experiences as students can be particularly problematic, as candidates have spent many years observing teaching but they were not privy to teachers' pedagogical decision-making or the theory that undergirds their practices (Loughran, 2006). This can provoke candidates to enact past practices they have witnessed rather than practices that are currently advocated, and underestimate the complexity of teaching (Loughran, 2006). While familiarity with the classroom context promotes high initial self-efficacy, discovering how thinking and acting like a teacher is much more difficult than it appears can quickly diminish teacher candidates' confidence (Falkenberg \& Smits, 2010; Loughran, 2006).

\section{Teacher Mentorship Programs}

Through familiarizing a novice with their role under the guidance of someone who is more experienced, mentorship programs have been shown to enhance the confidence and competence of teachers and transform a culture of isolation to one of collaboration (Brewster \& Railsback, 2001; DePaul, 2000; Falkenberg \& Smits, 2010; Fullan et al., 2006; Rowley, 1999; Sullivan, 1999). Consequently, in-service mentorship programs are advocated widely, with mentorship between pre-service and in-service teachers perceived to be conventional wisdom (CochranSmith \& Lytle, 1999; DePaul, 2000; Falkenberg \& Smits, 2010; Long \& Stuart, 2004; Loughran, 2006; Mueller \& Skamp, 2003; Sullivan, 1999).

Various models of mentorship programs for pre-service and beginning teachers have become prominent internationally (Hoban, Ashby, Malderez, \& Tomlinson, 2009). In attempts to identify the salient features of effective programs, Hoban and colleagues (2009) completed a review of 170 studies that represented the international research literature focused on mentoring pre-service, probationary, and recently qualified teachers. Their review documented that mentoring had been shown to increase the confidence, professional growth, self-reflection, and problem-solving abilities of novices and their mentors. Additionally, it fostered enhanced collegial collaboration and lead to a consolidation of mentors' professional identities. Drawbacks to mentoring identified included the potential for increased stress. Whereas, some mentors experienced stress as a function of increased workloads attributed to meeting the needs of a novice, in lieu of feeling supported, some novices felt stress as a function of being bullied by 
their mentor and/or discouraged from using innovative practices.

Hoban and colleagues (2009) concluded conditions for successful programs included the development of effective procedures for pairing and selection of mentors, contextual supports for mentoring, and the preparation of mentors through exposure to mentoring strategies. Effective mentorship was found to be dependent in part, on the will of the novice to be mentored and the skill of their assigned mentor. Questions raised included the potential benefits of separating the mentorship of pre-service candidates by an associate teacher from the assessment of their teaching competence. Additionally, Hoban and colleagues (2009) cautioned that traditional apprenticeship mentorship held the potential to reinforce long-standing transmission-oriented teaching, rather than encourage candidates to implement constructivist-oriented methods.

In order to challenge the status quo and promote collaborative inquiry and practice, Cochran-Smith and Lytle (1999, 2009) advocated the development of reciprocal learning mentorship models. In contrast to apprenticeship models wherein the mentor is assumed to be the more knowledgeable other, within a reciprocal learning model novices and mentors adopt an inquiry stance, engage in collaborative reflection, and co-construct new understandings (Cochran-Smith \& Lytle, 1999, 2009). Reciprocal learning mentorship programs are founded on principles of interdependence, mutual respect, and acknowledgment that novice and mentor participants will learn from and with one another, through critical inquiry focused on socially constructing knowledge (Cochran-Smith \& Lytle, 1999, 2009; Le Cornu \& Ewing, 2008).

Concomitant with traditional apprenticeship mentorship between pre-service and experienced teachers has been an expectation that this model will prepare candidates for autonomous classroom practice (Bullough et al., 2002; Bullough et al., 2003; Gardiner \& Robinson, 2009). However, preparation for independent practice is inconsistent with the current emphasis on reflective collaborative practice (Cochran Smith \& Lytle, 2009; Fullan et al., 2006; Knight, 2009). Moreover, Le Cornu and Ewing (2008) asserted that to prepare future teachers for sustained commitment to collegial collaboration, pre-service field experiences must go beyond developing candidates' collaborative and reflective abilities, and also promote reciprocity. That is, candidates should be provided with field experiences that explicitly foster interdependence and promote candidates' commitment to the belief that they "have an important role in providing personal and professional support to each other (Le Cornu \& Ewing, 2008, p. 1808).”

\section{Field Experience Dilemmas}

Promoting field-based reciprocity between candidates can be difficult, as most commonly their practicums are completed individually in classrooms under the supervision of hosting associate teachers and university faculty supervisors, who share mentoring and evaluating responsibilities (Foster, Wimmer, Winter \& Snart, 2010). While this model continues to be prevalent, significant dilemmas have been identified in perpetuating this "norm" (Falkenberg \& Smits, 2010; Long \& Stuart, 2004; Loughran, 2006). Moreover, the field lacks sufficient empirical evidence of the effectiveness of alternative practicum models (Foster et al., 2010).

A persistent problem with many field experience models is the potential disconnect between understandings derived through coursework and the practical knowledge candidates develop through their classroom experiences (Cochran Smith \& Lytle, 1999, Falkenberg \& Smits, 2010; Loughran, 2006). In part, this has been attributed to the fact that university faculty often have little involvement in candidates' field-based experiences (Foster et al., 2010). Thus, the relation between candidates' coursework and field experiences may not be examined (Long $\&$ Stuart, 2004). Furthermore, teachers' pedagogical decision-making may not be analyzed or 
understood (Loughran, 2006). Assuming that this will occur in the field is problematic, as associate teachers are focused primarily on providing learning opportunities for their students, which may render it difficult for them to devote attention to articulating their pedagogical reasoning in attempts to scaffold the growth of teacher candidates (Falkenberg \& Smits, 2010).

Moreover, lack of communication and collaboration between universities and their school-based partners may create situations where there is little understanding of the practices advocated and implemented in one setting and the other (Foster et al., 2010). Indeed, lack of communication can result in candidates receiving "mixed messages" particularly if they have insufficient support in the field during educational paradigm shifts (Le Cornu \& Ewing, 2008).

Reconceptualising teacher education as a process of enculturation into supportive learning communities has led to the creation of programs where dyads of candidates take part in shared practicum experiences (Bullough et al., 2002; Bullough et al., 2003; Gardiner \& Robinson, 2009; Goodnough et al., 2009; Walsh \& Elmslie, 2005). Investigations have documented that paired practicum participants perceived this model to enhance collegial collaboration, support, and learning for both candidates (Bullough et al., 2002; Bullough et al., 2003; Gardiner \& Robinson, 2009; Goodnough et al., 2009). While potential drawbacks included candidate compatibility, competition, lack of freedom to innovate, and/or enhanced dependency, researchers concluded they were outweighed by the benefits of paired practicum experiences (Bullough et al., 2002; Bullough et al., 2003; Gardiner \& Robinson, 2009; Goodnough et al., 2009; Walsh \& Elmslie, 2005).

The study described herein investigated the perceptions of participants in a paired practicum peer mentorship program. Although previous research had investigated the experiences of paired practicum participants at the same stage of program completion (Bullough et al., 2002; Bullough et al., 2003; Gardiner \& Robinson, 2009; Goodnough et al., 2009; Walsh, \& Elmslie, 2005), it appeared that little if any research had investigated a reciprocal learning model of paired practicum mentorship between novice and more experienced teacher candidates.

\section{Methodology}

This longitudinal study consists of three phases, with this paper focused primarily on the second. The first phase (October 2007-April 2008) investigated the experiences of 17 dyads of teacher candidates who participated in the pilot project. The second phase (January 2009-April 2009), described herein, investigated candidates' perceptions of the first year of full implementation of the peer mentorship program. Data collection is in progress for the third phase (January 2010April 2010) investigating the second year of full implementation.

\section{Context}

This study took place within a 4-year concurrent education program offered at a small regional campus of an Ontario Faculty of Education. The regional campus serves a total population of approximately 700 teacher candidates in years one to four, with between 140 and 230 in each program year. The practicum component of this program was developed in part, based on the belief of the founding director that early and ongoing immersion in the field would enhance the development of effective teaching skills. Consequently, the program includes a placement in the same classroom each Monday (excluding exam periods) from late October through March, for a total of 15 single days followed by one full week in April, for a total of 20 days per annum. This practicum structure was implemented for years one though three, with fourth year candidates 
participating in two four-week block placements.

\section{Peer Mentorship Program Development}

The practicum peer mentorship program was developed within the theoretical framework of social learning theory (Bandura, 1986; Vygotsky, 1986) by the current program director and faculty. Specifically, it sought to provide scaffolding through opportunities for first year candidates to be provided with the support and assistance of a second or third year candidate who was perceived to be a more experienced other within the novice's zone of proximal development (Vygotsky, 1986). The mentorship program also drew on Bandura's (1986) theory of observational learning and sought to enhance candidates' self-perceptions of competence by providing vicarious experiences watching teaching modelled by a peer. The saliency of vicarious experiences is related directly to how closely the observer identifies with the skills and context of the individual observed (Bandura, 1986). Consequently, we believed that observing one another teach in the same classroom held the potential to positively impact the efficacy of both candidates.

The peer mentorship program was intended to foster collaboration and engagement in reciprocal learning, as well as provide a vehicle for upper year candidates to share understandings acquired throughout the program with year one candidates. In part, the suggested activities were based on the New Teacher Induction Program (NTIP) that provides for mentoring of first year teachers by experienced Ontario teachers (Ontario Ministry of Education, 2006). While the NTIP program notes the importance of tailoring mentoring activities to participants' needs, recommended experiences include classroom observations, co-planning, professional dialogue, and shared professional development (Ontario Ministry of Education, 2006).

In keeping with many of the suggested NTIP experiences, the recommended practicum peer mentorship activities included classroom observations, collaborative planning, team teaching, and professional dialogue. Mentors were expected to become familiar with the strengths and needs of their novice and model professionalism in planning, implementing, and assessing student learning. Novices were expected to initially ask questions, set goals, observe carefully, and engage in collaborative reflection, with their involvement in co-planning and coteaching increasing gradually throughout the duration of the practicum. Dyads placed in the same classroom were expected to meet for thirty minutes per practicum day to review lessons, co-plan, share observations, and reflect on new learning, with their associate teachers participating in these meetings whenever possible. Importantly, candidates were expected to be non-evaluative with one another. In keeping with our past practices, associate teachers and university faculty advisers shared responsibilities for the assessment and evaluation of candidates' teaching.

\section{Pilot Mentorship Program}

In the year prior to the study described herein, a pilot project was implemented with seventeen pairings of novice first year and mentor third year candidates placed in the same practicum classrooms. All pairings were located in the same school, where the program was developed collaboratively with the pilot site principal who requested that all seventeen staff members participate as associate teachers, as she perceived that hosting the mentorship program held the potential to affect student achievement positively. Analysis of the perceptions of teacher candidates and associate teachers gathered through focus group sessions revealed the strengths of the pilot program to be the abundant opportunities for reciprocal learning, which were perceived 
to foster the growth of both participating candidates. Challenges included associate teachers' lack of clarity with respect to the differentiated expectations of novice and mentor candidates, in addition to mentors' perceptions of the additional time and effort required to assist the novice. Overall, the benefits of the pilot program were perceived to outweigh the challenges. Consequently a paired practicum peer mentorship program was implemented with all novice candidates during the 2008-2009 academic year.

\section{Full Implementation of Practicum Peer Mentorship}

As there were 227 first-year and 140 third-year candidates, full implementation necessitated the development of pairings between first-year candidates and either a second-year candidate (with 4 weeks practicum experience), or a third-year candidate (with 8 weeks practicum experience). Wherever possible, novices and mentors were placed in the same classroom with the same associate teacher. In order to differentiate roles and responsibilities, mentors began their practicum in October with novices commencing at the beginning of the second term in January. This change from the pilot program was intended to clearly delineate for associate teachers the roles of mentors and novices, as well as provide mentors with opportunities to develop understandings of the classroom context in preparation for later supporting the novice.

In order to provide consistent information with respect to expectations, all participating teacher candidates took part in pre-program workshops that reviewed the rationale for the peer mentorship program, the importance of professionalism, and the expectations of reciprocal learning. Consistent with the pilot program, intended mentoring experiences included classroom observations, collaborative planning, co-teaching, and professional dialogue. Additionally, it was recommended that Curriculum Methods course instructors include an increased emphasis on mentorship and collaborative practice, with particular attention to strategies for reciprocal learning through co-planning and co-teaching.

The practicum handbook provided to all teacher candidates and associate teachers was revised to include an overview of the peer mentorship program together with expectations of novice and mentor candidates. In attempts to build school board partners' understandings, the rationale for the mentorship program was explained in correspondence soliciting associate teachers willing to host two teacher candidates.

\section{Participants}

A total of 454 teacher candidates were involved in the peer mentorship program. All 227 firstyear candidates were allocated a mentor, primarily on the basis of requests for practicum placements in the same geographic area or school board. The mentor group was comprised of 117 third-year candidates and 110 second-year candidates. A total of 211 pairings were placed as dyads in the same classrooms. Due to geographical constraints or lack of associate teachers in some locations who were willing to host two candidates, 16 novices were not assigned mentors in the same classrooms. In these instances, novices were assigned mentors placed in another classroom in the same school or in a different school in close geographic proximity.

Approximately one third of the 454 potential participants elected to take part in this study, which was presented as an opportunity to provide feedback that would be used to improve the peer mentorship program. The 166 respondents included 70 year-one candidates, 40 year-two candidates, and 44 year-three candidates, who were placed in the same classroom as their partner. Of the 32 candidates who were not placed in the same classroom as their mentorship 
partner, respondents included six year-one novices, and six year-two or year-three mentors.

\section{Data Collection and Analysis Procedures}

Data were gathered through responses to electronic surveys completed anonymously at the conclusion of the mentorship program. Participants were asked to use a five-point Likert ordinal scale to rate the frequency with which they engaged in each of the intended activities with their mentorship partner. They also used a five-point Likert ordinal scale to rate their perceptions of how prepared they were for their role in the program, as well as how beneficial the mentorship program was for novices, mentors, and associate teachers.

Additionally, to solicit participants' perceptions of the factors that affected their peer mentorship experiences, the survey included the following four open-ended questions:

1. Comment on the effectiveness of the strategies used to prepare you for your role in the mentorship program.

2. Please describe the strengths of the Concurrent B.Ed. mentorship program.

3. Please describe any aspects of the Concurrent B.Ed. mentorship program that require improvement and suggest alternative changes.

4. Do you have any additional comments about the Concurrent B.Ed. mentorship program that you would like to make?

In April 2009, an invitation was emailed to all potential participants who were asked to complete the survey within a two-week time period, with a reminder inviting them to do so sent one week later. Anonymity was assured, with all responses returned to a research assistant who signed a confidentiality agreement. In clustering responses, the research assistant stripped these data of any identifying information (e.g., names of associate teachers). The responses of all cases where the mentor and novice were not placed in the same classroom were clustered for analyses.

While descriptive statistics were used to analyze the quantitative data, participants' anecdotal responses were analyzed through coding and categorizing of key idea units as described by Creswell (2002). The idea units were next collapsed into categorical clusters and themes representing participants' perceptions. Two researchers independently reviewed the qualitative data, prior to meeting to present their interpretations and negotiate a shared understanding. Following this process the key overall finding was that this program fostered collaborative practice, with two broad themes representing the impact of doing so. The most prominent theme was the increased support peer mentorship provided for teacher candidates, with the second theme the complexities of responding to the paradigm shift of shared practicum experiences.

In presenting our findings we include the mean Likert ordinal response to each survey question, together with supportive quotes that illustrate the themes identified through analysis of participants' anecdotal responses. This research design and format of presentation contextualizes the saliency of participants' responses, while also giving voice to their perceptions of the factors that affected the quantitative results (Gay \& Airasian, 2003).

\section{Findings}

Analysis of the survey responses revealed that the peer mentorship program achieved the objective of fostering collaborative practice amongst candidates in the practicum setting. Indeed, most participants who were placed in the same classroom setting frequently engaged in the 
recommended mentorship activities. These included collaborative planning, teaching, and reflection, as well as engaging in dialogue about how to respond to the expectations of their associate teacher and those of this teacher education program (e.g., lesson template use). Table 1 outlines the mean frequency with which candidates reported taking part in these activities.

\section{Table 1}

Engagement in Collaborative Activities

\begin{tabular}{llllll}
\hline Activities & \multicolumn{2}{l}{ Same Class Placement } & \multicolumn{2}{c}{ Different Class Placement } \\
& Year 1 & Year 2 & Year 3 & Year 1 & Year 2 or 3 \\
& $\mathrm{n}=70$ & $\mathrm{n}=40$ & $\mathrm{n}=44$ & $\mathrm{n}=6$ & $\mathrm{n}=6$ \\
& $\mathrm{M}$ & $\mathrm{M}$ & $\mathrm{M}$ & $\mathrm{M}$ & $\mathrm{M}$ \\
\hline BEd Program Expectations & 3.56 & 3.60 & 3.48 & 2.33 & 2.63 \\
Associate Teacher Expectations & 3.90 & 3.90 & 3.64 & 2.67 & 2.63 \\
Collaborative Lesson Planning & 3.80 & 4.05 & 4.02 & 2.17 & 2.75 \\
Team Teaching & 3.54 & 3.85 & 3.77 & 1.17 & 2.00 \\
Collaborative Reflection & 3.36 & 3.33 & 3.45 & 1.83 & 2.13 \\
\hline
\end{tabular}

Note. Items rated on 5-point scale ( $1=$ never, $2=$ seldom, $3=$ =sometimes, $4=$ usually, $5=$ consistently)

In engaging in these collaborative learning experiences, participants uncovered the strengths and challenges associated with implementing this peer mentorship program. Two key themes identified were the increased support this program provided for teacher candidates and the complexities of the paradigm shift to shared practicum experiences. The latter theme was further subdivided into several subthemes including the need to foster perceptions of teaching as collaborative practice, the importance of contextual supports, and the tensions negotiated by mentors as a function of the revised program expectations. The two themes are presented next.

\section{Support for Teacher Candidates}

Candidates rated their perceptions of how beneficial practicum peer mentorship was for novices, mentors, and associate teachers (Table 2). Not surprisingly, candidates' responses revealed perceptions that this program was most beneficial for novices placed in the same classroom as their mentor. Interestingly, the program was also perceived to be of moderate benefit to novices who were not placed in the same setting as their mentor partner. 
Table 2

Beneficial Effects for Participants

\begin{tabular}{llllll}
\hline & \multicolumn{2}{c}{ Same Class Placement } & \multicolumn{2}{c}{ Different Class Placement } \\
Program Participant & Year 1 & Year 2 & Year 3 & Year 1 & Year 2 or 3 \\
& $\mathrm{n}=70$ & $\mathrm{n}=40$ & $\mathrm{n}=44$ & $\mathrm{n}=6$ & $\mathrm{n}=6$ \\
& $\mathrm{M}$ & $\mathrm{M}$ & $\mathrm{M}$ & $\mathrm{M}$ & $\mathrm{M}$ \\
& 4.24 & 3.67 & 4.00 & 3.33 & 3.50 \\
Novices & 3.35 & 2.73 & 3.07 & 2.83 & 2.38 \\
Mentors & 3.41 & 2.95 & 2.70 & 3.17 & 2.50 \\
\hline
\end{tabular}

Note. Items rated on a 5-point scale ( $1=$ not at all, 2=minimally, $3=$ moderately, $4=$ very, 5=highly)

Consistent with the quantitative results, the most salient theme identified through analysis of participants' anecdotal responses was the support this program provided, particularly for novice candidates. An overwhelming majority (i.e., eighty-five percent) of novice respondents were extremely positive about participating in this program and identified its strength as the abundant support provided through collegial collaboration, which fostered increased confidence.

You have someone to rely on when you are stuck. Together you stand strong to figure things out and come up with ideas. (Novice)

There is someone there to help you come up with ideas and to teach with you. It allows us to have more confidence in ourselves as teacher candidates. (Novice)

Helps the novice generate lesson plans, gain resources, gain knowledge and understanding of team teaching. Helpful for both the novice and mentor in discussing different ideas and experimenting with them. Without my mentor I would have been lost on the first few days! (Novice)

Importantly, one third of respondents reported greater ease adopting an inquiry stance with their mentorship partner, than with their associate teacher. This increased willingness to seek answers to questions about expectations and the needs of students in their classrooms was perceived to clarify expectations, enhance understandings, and foster professional confidence.

The mentorship program allows for first year students to interact with another student teacher about the classroom they are in. It isn't always easy to talk about everything regarding the class with your associate teacher. I was less stressed out going into an unfamiliar environment when there was another student there with me. She gave me a lot of guidance as to how to deal with certain students. (Novice) 
I believe that the mentorship program is beneficial as it gives the first year student the opportunity to feel more comfortable to ask more questions, and to see exactly what is expected of them in practicum. (Novice)

Enables both students to ask questions without feeling silly or stupid. (Year 3 Mentor)

The vast majority of mentor respondents (i.e., eighty percent) echoed the novices' perceptions of the benefits of enhanced collaboration and reciprocal learning. While many noted that novices derived the greatest benefit from the program, fifty percent of mentor respondents highlighted how mentoring enabled them to consolidate their learning and articulate their teaching beliefs, which led to a stronger sense of their professional identity as a teacher.

As a mentor it got me to think more about what I was doing because I had to explain some of the strategies I used. Commenting on my novice's strategies also got me to think critically. (Year 3 Mentor)

This program gave both of us great experience. I had the chance to take the lead and explain teaching to someone who had no experience. This helped me to further understand my own role. It kept me on task and working hard because I had to be a role model for someone. It definitely taught me the importance of teamwork. (Year 2 Mentor)

The biggest strength of the program was that I learned about who I was as a teacher. Sharing my different beliefs on classroom management and what it means to be a teacher really helped me grow. (Year 3 Mentor)

Importantly, over the duration of the program novices and mentors appeared to increase their perceptions of the benefits of the program.

The idea at first seemed horrible, but things turned out pretty well. I think that more opportunities for team teaching help the mentor and the novice. (Year 3 Mentor)

At the beginning I was unsure about the mentorship program. However, after a couple of months into the program I felt it is to everyone's benefit. Knowing another fellow student who was in my position last year was going to be in the classroom with me, made me less stressed and my transition to the class was smoother. I also had the support of someone to ask questions without disrupting the teacher in front of the class. Team teaching in the beginning was also important and fun. My mentor was a great support and helped me through lesson plans and answered any of my questions. I highly recommend this program. (Novice)

As a function of their positive experiences, fifteen percent of novice respondents expressed excitement at the prospect of transitioning to the role of mentors and providing support to a novice. Importantly, these expressions of interest were unprompted, as the survey did not solicit candidates' attitudes towards future participation in the peer mentorship program.

I can't wait for next year to become a mentor and help a first year student through 
everything I just went through. (Novice)

Being in first year I was not scared and it didn't force me to be a leader. Now, I feel that I am ready to be a leader! (Novice)

This is a great idea! I'm excited to be a mentor next year! (Novice)

I loved my time in placement this year and can not wait for next year! I really enjoyed the mentorship program and would love to be a part of it again! (Novice)

In sum, the mentorship program was perceived to be beneficial by the majority of participants, who appeared to value the support they derived through the collaborative learning it fostered.

\section{Complexities of the Paradigm Shift}

Nonetheless, altering the concurrent education program expectations to engagement in shared rather than individual practicum experiences was a paradigm shift that appeared to bring forth challenges for teacher candidates, associate teachers, and faculty members. These included the complexities of fostering perceptions of teaching as collaborative rather than individual practice; developing contextual supports for teacher candidates and associate teachers; and, the tensions experienced by mentors who after engaging in individual field experiences for one or two years, were asked to share their field placements and collaborate to support their partner's professional growth. Not surprisingly, these complexities brought forth many dilemmas.

\section{Teaching as Collaborative Practice}

One third of participants' responses revealed that candidates and/or associate teachers appeared to hold perceptions of "teaching" as independent, rather than collaborative practice. In some instances this appeared to provoke associate teachers to discourage candidates from engaging in co-planning and co-teaching. In other instances candidates' perceptions of teaching as individually facilitating student learning, seemed to promote competition for "teaching time" rather than shared responsibility for co-teaching.

Associate teachers need to be more aware of the expectations. My novice and I very rarely got to co-plan or co-teach any lessons. (Year 2 Mentor)

Ifelt that I was not given enough time for my own lessons. (Novice)

Mentors should be aware that their novice should be co-teaching with them. I never cotaught with my mentor because she felt it was unnecessary. (Novice)

Neither gets as much experience as if they were on their own in the classroom. The novice and the mentor are continually battling for teaching time. (Year 3 Mentor)

Additionally, in lieu of experiencing freedom to innovate, some novices perceived their contributions to co-planning to be undervalued by their mentor partner. More positively, this was perceived to decrease as novices gained experience in the classroom context. 
I found that my mentor was a very dedicated and over achieving individual, which is great. However with team teaching I sometimes felt that my ideas were vetoed because my mentor felt her idea was better or maybe it was because she really felt my contribution would just not work the way she saw the lesson. However this happened less and less as the year went on. (Novice)

\section{Development of Contextual Supports}

A significant challenge of this model was securing paired field placements for all candidates. Lack of availability in some locations necessitated placing 16 novices in different classrooms than their mentors. As this was unanticipated, there were no contextual supports developed to facilitate mentorship between candidates in different settings. Not surprising, these anomalous models were not perceived as positively. Respondents reiteratively stated that mentorship partners should be placed in the same classroom.

The problem that I have with this program was that my mentor was placed in a different school. She did not attempt to contact me or aid me in any way. It was not very helpful to me at all. Mentors should be in the same class as the first year student. (Novice)

My mentee was in the other classroom and although I did enjoy her presence and working with her I found it difficult to assist her as I would have if she was placed with me and I could see her actually teach. (Year 2 Mentor)

In rating their perceptions of their preparation for their respective novice or mentor roles (Table 3), most participants indicated they were moderately or very well prepared.

Table 3

Self-Perceptions of Preparation

\begin{tabular}{llllll}
\hline & \multicolumn{2}{c}{ Same Class Placement } & \multicolumn{2}{c}{ Different Class Placement } \\
& Year 1 & Year 2 & Year 3 & Year 1 & Year 2 or 3 \\
& $\mathrm{n}=70$ & $\mathrm{n}=40$ & $\mathrm{n}=44$ & $\mathrm{n}=6$ & $\mathrm{n}=6$ \\
& $\mathrm{M}$ & $\mathrm{M}$ & $\mathrm{M}$ & $\mathrm{M}$ & $\mathrm{M}$ \\
\hline Preparation for Mentorship & 3.77 & 3.50 & 3.50 & 3.33 & 2.75 \\
\hline
\end{tabular}

Note. Items rated on a 5-point scale (1=not at all, 2=minimally, 3=moderately, 4=very, 5=highly)

However, analysis of participants' anecdotal comments revealed that the methods intended to prepare candidates for paired practicums were not always implemented. For instance, it was recommended that Curriculum Methods courses include an explicit focus on reciprocal learning through co-planning and co-teaching strategies. While some year two candidates reflected 
positively on these experiences, others reported that these support mechanisms were not in place.

I was very prepared to go into a classroom after all the workshops and class experience I gained. It made my transition much easier and less stressful. In the classroom situation I used many methods and strategies pointed out by the experienced and helpful prof. (Year 2 Mentor)

We did not discuss mentoring in our methods class so the presentation was the first time we were provided with an opportunity to learn our role. (Year 2 Mentor)

I don't believe we were really told what we were supposed to do until one week before. I did not feel prepared at all and I know that my novice had no idea what he was supposed to be doing. (Year 2 Mentor)

Additionally, it appeared that many of our board partners were unprepared for the practicum program change and that it was ineffective to provide information about the peer mentorship program to school boards through written correspondence and to associate teachers through the practicum handbook. Forty percent of respondents recommended enhancing associate teachers' understandings of the goals of the mentorship program, particularly the expectations of novice and mentor candidates.

Associate teachers need to understand the very purpose of the mentorship program, because my associate definitely did not understand at all. (Year 2 Mentor)

Associate teachers need to be better informed on some things. (Novice)

Having all the associate teachers understand the meaning of a novice and a mentor and how much each student teacher is supposed to be teaching in a day. (Novice)

\section{Tensions Negotiated by Mentors as a Function of Revised Expectations}

Most mentors took part in their first field placements without peer support. In some instances, they appeared to view the introduction of the peer mentorship program negatively or perceive it as inequitable.

I believe it would have been an awesome experience if my mentor "liked" it, rather she did not like it. (Novice)

\section{Training the competition creates animosity. (Year 2 Mentor)}

I feel first year would benefit a lot more from the old style of the program, where they have their own class and set expectations. (Year 2 Mentor)

In part, mentors' perceptions of inequity were promoted by the adoption of anecdotal progress reports for novices that detailed their overall strengths and growth areas, in lieu of the past practice of evaluating their competence by rating their performance (i.e., inadequate, satisfactory, proficient, exemplary) in many areas. This change in the assessment of novices' 
practicum experiences was implemented at the same time as the mentorship program. Fifteen percent of the year-two respondents shared perceptions that the status quo should have been maintained, with novices experiencing the same formal evaluations used previously.

I think the year one's should have to be evaluated so that they understand what it feels like and are more prepared to deal with it later. (Year 2 Mentor)

There should be specific guidelines for the first years about what they are supposed to do and some sort of follow-up to ensure they have done it, such as formal evaluations for first years. (Year 2 Mentor)

We are very appreciative of our teacher candidates' willingness to share their perceptions of participating in this program. Their insights have enhanced our understandings of the complexities of this change and have provided direction for refinement of this program.

\section{Discussion}

We acknowledge the unique context of this concurrent education program, particularly the opportunity to have a designated day of the week throughout the academic term allocated as a practicum day for all first, second, and third year candidates. Nonetheless, the findings of this investigation provide important sights for the field of teacher education about the benefits and complexities of implementing practicum peer mentorship. These insights may be particularly relevant to those developing or refining concurrent education programs and/or two-year consecutive Bachelor of Education programs.

Consistent with the findings of others (Gardiner \& Robinson, 2009; Goodnough et al., 2009; Walsh \& Elmslie, 2005), the experiences of participants in this program support the implementation of paired practicum teaching, despite the potential challenges of candidate compatibility, competition, and freedom to innovate. Our findings document how, analogous to the experiences of participants in other mentorship programs (Hoban et al., 2009), practicum peer mentorship can foster candidates' self-confidence and professional growth. Importantly, engaging in mentorship activities with a partner within their zone of proximal development (Vygotsky, 1986) who was not responsible for evaluating their teaching competence, appeared to foster interdependence and increase candidates' willingness to adopt the inquiry stance requisite to collaborative professional learning (Cochran-Smith \& Lytle, 2009; Le Cornu \& Ewing, 2008).

Significantly, this program promoted collaborative field-based learning between candidates (Le Cornu \& Ewing, 2008). Collaborative educational practice is advocated widely (Bullough et al., 2003; Cochran-Smith \& Lytle, 1999; Fullan et al., 2006). However, developing productive collaborative learning communities requires time and ongoing attention to promoting reciprocity (Cochran-Smith \& Lytle, 1999, 2009; Fullan et al., 2006; Knight, 2009). We hope that the positive experiences of many participants in this program, particularly those who were novices, will help to lay the foundation for continued collaborative practice within and beyond this concurrent education program. Indeed novice participants' spontaneous expressions of interest in becoming mentor candidates provide reason for optimism that there is the potential for this to occur (Le Cornu \& Ewing, 2008).

Educational paradigm shifts are complex, with those involving the creation of collaborative learning communities necessitating the development of strong support systems (Cochran-Smith \& Lytle, 1999; Le Cornu \& Ewing, 2008). Additionally, requisite to the 
implementation of effective mentorship programs are the development of contextual supports (Hoban et al., 2009). Regrettably, in some instances it appeared that the support systems developed for the practicum peer mentorship program were inadequate and/or ineffective.

The pilot mentorship program was developed collaboratively with our board partner in one school site. On the basis of perceptions of the effectiveness of the pilot, we moved quickly to full implementation without involving many of our partner boards in the decision-making process. In doing so, we did not acknowledge the importance of collaboration in the development of innovative field practicum models (Falkenberg \& Smits, 2010). Not surprisingly, addressing the intent of the implementation of practicum peer mentorship through the provision of written material to our school board partners appeared to be insufficient. Program changes that involve paradigm shifts in the expectations of teacher candidates require close collaboration and communication with school board administrators and associate teachers (Falkenberg \& Smits, 2010; Le Cornu \& Ewing, 2008). Indeed the ongoing effectiveness of this program is in part, contingent upon the understandings and support of our field-based partners. We hope that in revising our communication methods and engaging our board partners in collaboratively refining this program, we will be able to create stronger partnerships and enhance associate teachers' willingness to promote collaborative practice and host dyads of candidates.

In addition to fostering enhanced field-based support for this program, we need to create support structures for anomalous mentorship pairings. Given that our candidates are able to request their practicum location from a selection of 13 partner school boards (in part, to develop contacts for future employment), it is possible that demographic constraints will continue to necessitate some mentorship pairings where candidates are not placed in the same classroom. Consequently, we need to create opportunities for these candidates to engage in reciprocal learning through spending time in one another's field placement settings. We concur with Hoban and colleagues' (2009) assertion that attention to the creation of compatible mentorship pairings would be ideal. However, we recognize that this may be difficult in this context where candidates self-select the geographic location of their practicum, and are in the early stages of developing their professional identities.

As we embarked on full implementation of this program, we acknowledged the importance of explicitly connecting candidates' field experiences with their coursework (Falkenberg \& Smits, 2010; Long \& Stuart, 2004). Therefore, we advocated that Curriculum Methods courses focus on mentorship and collaborative practice, with particular attention to strategies for reciprocal learning. However, not all candidates perceived their course experiences to have provided this support. As such, we need to strengthen the emphasis on reciprocal learning throughout candidates' coursework experiences in our program. Additional supports for mentorship participants, such as workshops focused specifically on collaborative practice, with attention to strategies for co-planning and co-teaching, may also be warranted.

Through examining our participants' perspectives, we have learned that we may have unintentionally provided them with "mixed messages" about their roles and responsibilities. Our intent in differentiating between the roles of mentor and novice candidates was to be responsive to the pilot program participants' recommendations. However, clearly demarcating the differentiated roles of candidates may have fostered perceptions of this peer mentorship program as an apprenticeship, rather than a reciprocal learning model (Cochran-Smith \& Lytle, 1999, 2009; Hoban et al., 2009). This highlights the importance of explicitly promoting teacher candidates' and associate teachers' increased understandings of the expectations for reciprocal learning and peer scaffolding through collaborative practice. In fostering these understandings, it may be beneficial to outline how this model differs from traditional apprenticeship mentorship. 
We also acknowledge that the apprenticeship of observation (Lortie, 1975) may have contributed to the reluctance of some candidates to engage in collaborative practice. Moreover, our teacher education practices may have reinforced rather than disrupted this perception, as candidates were told about reciprocal learning through co-teaching and co-planning, yet these practices are not modelled by many instructors in our program. We concur with Loughran (2006) that modelling the practices we advocate and articulating our pedagogical decision-making as we do so, may enhance candidates' abilities to follow suit.

Importantly, this study revealed that most novices adopted positive perceptions of practicum peer mentorship and that many appeared to feel responsible for supporting future novices, thereby exhibiting the reciprocity requisite to sustained commitment to collaborative practice (Le Cornu \& Ewing, 2008). As these candidates assume the roles of mentors, we are cautiously optimistic that some of the tensions encountered by candidates who had not benefitted from this program as novices, will be diminished, if not eradicated. In order to delineate whether this occurs, our longitudinal study seeks to capture the perceptions of 2009 novice participants, as they transition to the role of mentors in 2010 .

Teacher education programs are imperfect and incomplete (Loughran, 2006). This model of teacher candidate practicum peer mentorship was no exception. Yet, consistent with the assertions of others (Bullough et al., 2003; Gardiner \& Robinson, 2009; Goodnough et al., 2009; Walsh \& Elmslie, 2005), the results of this study reveal that the benefits of paired practicums outweigh the drawbacks. Our findings document that despite the complexities of practicum mentorship between candidates, it holds the promise to prepare future educators as collaborative practitioners. Data collection is ongoing as we continue to glean participants' perceptions and use these insights to refine this reciprocal learning model of practicum peer mentorship.

\section{Concluding Thoughts}

Teacher education is complex, multifaceted, and lays the foundation for educational practice (Cochran-Smith \& Lytle, 1999; Loughran, 2006). In this era where the importance of teacher collaboration is recognized widely (Cochran-Smith \& Lytle, 2009; Fullan et al., 2006; Gardiner \& Robinson, 2009; Knight, 2009), supporting candidates' abilities to engage in collaborative rather than autonomous practice holds the potential to better prepare them for their future challenges as members of the teaching profession (Le Cornu \& Ewing, 2008). To this end, the findings of this study may provide direction for teacher educators interested in enhancing collegial collaboration amongst candidates through the development of opportunities for peer scaffolding and reciprocal learning in the practicum setting.

\section{Acknowledgements}

The authors acknowledge the invaluable contributions of the Practicum Officer Deanne Osborne and the Practicum Office staff throughout implementation of all phases of the practicum peer mentorship program. 


\section{References}

Bandura, A. (1986). Social foundations of thought and action: A social cognitive theory. Englewood Cliffs, NJ: Prentice-Hall.

Brewster, C., \& Railsback, J. (2001). Supporting Beginning Teachers: How administrators, teachers and policymakers can help new teachers succeed. Portland, OR: Northwest Regional Education Laboratory.

Bullough, R. V., Young, J., Birrell, J. R., Clark, D. C., Egan, M. W., Erickson, L., Frankovich, M., Brunetti, J, \& Welling, M. (2003). Teaching with a peer: A comparison of two models of student teaching. Teaching and Teacher Education, 19(1), 57-73.

Bullough, R. V., Young, J., Erickson, L., Birrell, J. R., Clark, D. C., \& Egan, M. W. (2002). Rethinking field experience: Partnership teaching versus single-placement teaching. Journal of Teacher Education, 53 (1), 68-80.

Cochran-Smith, M., \& Lytle, S. L. (1999). Relationships of knowledge and practice: Teacher learning communities. Review of Research in Education, 24, 249-305.

Cochran-Smith, M., \& Lytle, S. L. (2009). Inquiry as stance: Practitioner research for the next generation. New York: Teacher College Press.

Creswell, J. W. (2002). Educational research: Planning, conducting, and evaluating quantitative and qualitative research. Upper Saddle River, NJ: Merrill Prentice Hall.

DePaul, A. (2000). Survival guide for new teachers: How new teachers can work effectively with veteran teachers, parents, principals, and teacher educators. Washington, DC: U.S. Department of Education. Retrieved April 29, 2008 from http://www.ed.gov/teachers/become/about/survivalguide/title.html

Falkenberg, T., \& Smits, H. (Eds.). (2010). Field experiences in the context of reform of Canadian teacher education programs (Vol. 1).Winnipeg, Canada: Faculty of Education of the University of Manitoba.

Foster, R., Wimmer, R., Winter, M., \& Snart, F. (2010). Field experiences in teacher education: What is and what could be - A case study of the University of Alberta. In Falkenberg and Smits (Eds.), Field experiences in the context of reform of Canadian teacher education programs (Vol. 2, pp. 187-224). Winnipeg, Canada: Faculty of Education of the University of Manitoba.

Fullan, M., Hill, P., \& Crevola, C. (2006). Breakthrough. Thousand Oaks, CA: Corwin Press.

Gardiner, W., \& Robinson, K. S. (2009). Paired field placements: A means for collaboration. The New Educator, 5, 81-94.

Gay, L. R., \& Airasian, P. (2003). Educational research: Competencies for analysis and applications (7th ed.). Upper Saddle River, NJ: Merrill/Prentice Hall. 
Goodnough, K., Osmond, P., Dibbon, D., Glassman, M., \& Stevens, K. (2009). Exploring a triad model of student teaching: Pre-service teacher and cooperating teacher perceptions. Teaching and Teacher Education, 25, 285-296.

Hoban, A. J., Ashby, P., Malderez, A., \& Tomlinson, P. D. (2009). Mentoring beginning teachers: What we know and what we don't. Teaching and Teacher Education, 25, 207216.

Knight, J. (2009). Coaches as leaders of change. In M. Fullan (Ed.), The challenge of change (2nd ed., pp. 105-133). Thousand Oaks, CA: Corwin

Le Cornu, R., \& Ewing, R. (2008). Reconceptualizing professional experiences in pre-service teacher education: Reconstructing the past to embrace the future. Teaching and Teacher Education, 24, 1799-1812.

Long, D., \& Stuart, C. (2004). Supporting higher levels of reflection among teacher candidates: A pedagogical framework. Teachers and Teaching: Theory and Practice, 10(3), 275-290.

Lortie, D. (1975). Schoolteacher: A sociological study. Chicago, IL: University of Chicago Press.

Loughran, J. (2006). Developing a pedagogy of teacher education: Understanding teaching and learning about teaching. New York: Routledge.

Mueller, A., \& Skamp, K. (2003). Teacher candidates talk: Listen to the unsteady beat of learning to teach. Journal of Teacher Education, 54(5), 428-440.

Ontario Ministry of Education. (2006). New teacher induction program: Induction elements manual. Retrieved from http://tpfr.edu.gov.on.ca/NTIP/NTIP- EngInductionElementsMay5-Final.pdf.

Pajares, M. F. (1992). Teachers' beliefs and educational research: Cleaning up a messy construct. Review of Educational Research, 62(3), 307-332.

Rowley, J. B. (1999). The good mentor. Educational Leadership, 56(8), 20-22.

Sullivan, D. M. (1999). The best lessons: Learning to teach in a supportive context. In M. Scherer (Ed.), A better beginning: Supporting and mentoring new teachers (pp. 210-216). Alexandria, VA: Association for Supervision and Curriculum Development.

Vygotsky, L. S. (1986). Thought and language. Cambridge, MA: MIT Press.

Walsh, K., \& Elmslie, L. (2005). Practicum pairs: An alternative for first field experience in early childhood teacher education. Asia Pacific Journal of Teacher Education, 33(1), 521. 